This item was submitted to Loughborough's Research Repository by the author.

Items in Figshare are protected by copyright, with all rights reserved, unless otherwise indicated.

\title{
Young people and sport: from participation to the Olympics - introduction to the special issue
}

\section{PLEASE CITE THE PUBLISHED VERSION}

http://dx.doi.org/10.1080/17430437.2015.1124560

\section{PUBLISHER}

(c) Taylor \& Francis

\section{VERSION}

AM (Accepted Manuscript)

\section{PUBLISHER STATEMENT}

This work is made available according to the conditions of the Creative Commons Attribution-NonCommercialNoDerivatives 4.0 International (CC BY-NC-ND 4.0) licence. Full details of this licence are available at: https://creativecommons.org/licenses/by-nc-nd/4.0/

\section{LICENCE}

CC BY-NC-ND 4.0

\section{REPOSITORY RECORD}

Skirstad, Berit, Milena M. Parent, and Barrie Houlihan. 2019. "Young People and Sport: From Participation to the Olympics - Introduction to the Special Issue". figshare. https://hdl.handle.net/2134/20214. 


\title{
Young People and sport: from participation to the Olympics - \\ Introduction to the special issue
}

\author{
Berit Skirstad $^{\mathrm{a}}$, Milena M. Parent ${ }^{\mathrm{ab}}$ and Barrie Houlihan ${ }^{\mathrm{ac}}$ \\ ${ }^{a}$ Department of Cultural and Social Studies, Norwegian School of Sport Sciences, Oslo, \\ Norway \\ ${ }^{\mathrm{b}}$ School of Human Kinetics, University of Ottawa, Ottawa, Canada \\ ${ }^{\mathrm{c}}$ School of Sport, Exercise and Health Sciences, Loughborough University, Loughborough, UK
}

\begin{abstract}
The aim of this paper is to provide a context for the contributions which follow in this special issue. Attention is drawn to the range of possible motives for the increase in interest in youth sport evinced by a selection of major stakeholders including international sport federations, domestic federations and event organisers. The paper draws attention to the changing relationship between young peole and sport where the former are seen increasingly as a resource to help meet the organisational objectives of the latter. The paper concludes with a summary of, and commentary on, the nine papers in the special issue.
\end{abstract}

Keywords: young people, sports participation, elite sport, sport policy 


\section{Young People and sport: from participation to the Olympics -}

\section{Introduction to the special issue}

For domestic and international sport federations, sports event organisers and governments the relationship between young people and sport has been a long standing focus of interest and, at times, a focus of concern. For domestic sport organisations young people are: a pool of talent needed to maintain and expand domestic elite level competition; consumers of sports events either through attendance or through broadcast media; and as a resource that maintains the pyramid infrastructure of clubs, leagues and competitions. International sport federations would value young people for similar reasons with the addition that in recent years an increasing number of federations have begun to value young people as a resource for elite youth international sports competitions. Although the UCI organised its first Junior Road Race World Championships in 1975 and FIFA organised its first under 16 World Cup in 1985, similar international youth championships generally date from the present century. The history of multi-sport elite youth competitions is similarly recent with the first Commonwealth Youth Games held in 2000, the first JCC Maccabi Youth Games held in 1982 and the first Youth Olympic Games held in 2010.

For international sport federations and multi-sport event organisers the motives for investment in elite youth events are less clear. It is still rare for elite youth events to generate significant income through sponsorship or through the sale of broadcasting rights. A second, and more plausible, motive is a combination of the trend towards earlier specialisation and the concern by federations to ensure, at an early age, the commitment of their talented youngsters to their particular sport. The motives of the 
federations and event organisers overlap with those of governments, although the latter have a wider range of motives. For many governments international sporting success is an important soft power diplomatic resource (Grix and Houlihan 2014, Servaes 2012) and one way in which the utility of that resource is maintained is by heavy investment in specialist youth schools and academies. However, governments have additional motives for their involvement in youth sport which include social control, community integration and an increasing concern with the deleterious effects of an increasingly sedentary lifestyle (Grix and Carmichael 2012).

Irrespective of the particular motives of federations, event organisers and governments the combined effect of the increasing interest in promoting the involvement of young people in sport generally, and in elite sport in particular, is to foreground a range of issues concerned with their welfare and the impact of involvement in sport on young people. At the heart of much of the current debate around the relationship of young people to sport is whether they are conceptualised primarily as a resource to be utilised (although 'exploited’ might be a better term), a consumer group whose demands are to be met, or client group whose needs are being defined by others (teachers, youth worker and politicians, for example) and who have structures for doing sport imposed on them. 1960 is often noted in the history of UK government involvement in youth sport as a watershed with the catalyst for change being the publication of the report commissioned by the Central Council of Physical Recreation (CCPR 1960) in which the explicit concern was to explore what sport could do for young people: 'We have had particularly in mind, throughout our inquiries, the needs of young people. For them play is naturally appropriate; it is an essential part of the business of growing up' (CCPR 1960, 4). While reflecting the highly paternalistic attitudes of its time the underlying 
assumption was that sport was a resource for young people. Instrumental attitudes towards sport are still dominant in most governments, but they have been challenged by an increasingly instrumental attitude towards children. In short, the dominant conceptualisation of the relationship between young people and sport which can be summed up in the question 'What can sport do for young people?', is now being challenged by a contrary conceptualisation, emanating primarily from the international and domestic federations, but also from some event organisers and government, summed up as 'What can young people do for sport?'.

It is the increasing debate around the question of the appropriate relationship between young people and sport that has prompted this collection of papers. The collection covers a wide range of aspects of young people's involvement in sport. The opening paper by Parent and Harvey examines a community-based youth sport programme, Kids in Shape, and addresses issues and challenges of establishing and sustaining community sports activities, which will be familiar in many countries. The particular challenges of managing a complex network of local partners can often absorb as much energy and resources as the actual delivery of services to young people. Yet, it is undeniable that sport-based projects which are formed organically from within a community are much more likely to offer young people not only what adults think they need, but also what young people want from sport. In the conclusion to their paper, Parent and Harvey identify three 'key conditions for positive outcomes’ which are: adequate resources, especially time and finance; management expertise and capacity, especially skills in facilitating communication between partners and acting as an honest broker between interests; and evaluation capacity. It is this last condition that is most frequently neglected in programme design yet which is essential in attempting to ensure the long- 
term sustainability of programmes. Parent and Harvey’s Canadian case study is complemented by the research by Chalip and Hutchinson who, in their paper 'Reinventing Youth Sport: Formative Findings from a State-level Action Project', explore similar themes within an American context. Prompted by a concern with dropout from sport and a general decline in youth participation in major American sports, the research explored how programme design and delivery could be improved and made more attractive to young people. Based on extensive data collection from practitioners, the research was designed to identify the current problems in recruitment and retention in youth sport and suggest possible directions for solving those problems. The authors identified a number of thematic directions for improving youth sport including: the design and implementation of child-centred programming; the importance of enhancing the status of participatory youth sport programmes; the need to creatively develop and manage resources; the importance of training coaches to be sport and life skills mentors; the centrality of improving programming design so that it is attractive to traditionally underserved populations; and finally the often significant challenge of managing parents. As with the paper by Parent and Harvey, the study by Chalip and Hutchinson uses the insights derived from the analysis to offer recommendations for programme design and delivery.

The third paper, by Kristiansen, explores one of the central issues in relation to the welfare of young athletes, namely the challenge of balancing academic study, and by implication future job prospects, with participation in high level sport. Based on fieldwork conducted during the 2015 European Youth Olympic Festival (EYOF) with the Norwegian squad, Kristiansen examines how these youth athletes manage the competing pressures on their time and how the institutional context within which they 
are educated and participate in sport facilitates the balancing of these competing pressures, especially when they are involved in a high profile competition such as the EYOF. With a focus on the role of coaches, schools, parents, federations, and the National Olympic Committee and on the perceptions formed by the young athletes of the challenges of an intensely competitive international event, Kristiansen explores the reality of managing a dual career. Among the results of the study is the central importance of supportive parents and supportive schools that are willing to adapt workload and assignment deadlines for the student athletes. Also of importance is a domestic federation (and by implication coaches and other support staff) that recognises the context within which young talented athletes function. Although the organisers of the EYOF emphasised that the event was a 'learning experience', most young athletes saw it more traditionally - as an opportunity to compete at the highest level and to win medals. Even for those coaches that agreed with the organisers that the event was a learning event they nonetheless saw it as a significant developmental opportunity for the athletes where performance was important.

The paper by Smits, Jacobs and Knoppers complements the themes in Kristiansen’s paper, though its primary focus is not a particular event but the perceptions held by athletes and parents of the elite youth sport of gymnastics and especially the role of coaches. Gymnastics differs from most sports insofar as young people, especially females, often reach the highest competitive levels while still young. Adopting a Foucauldian lens through which to analyse the topic, Smits and colleagues explore how meaning is created, using the concept of sense-making, in the young athlete-coach relationship. Based on interviews with 14 elite female athletes and their parents, the 
authors describe an intense relationship in which both the athlete and their parent defer to the, often autocratic, coach. In particular, Smits et al. use the concept of sensemaking to explain how abusive behaviour by coaches was rationalised and was reinforced by a 'code of silence'. A particularly poignant observation is that 'The ways in which they made sense of their experiences, shaped by a coach-athlete dependency relationship, informed their idea of who they were and how they saw the world'. The paper concludes with a discussion of how the sport of gymnastics could be reformed so as to better protect young athletes.

The paper by Patterson and Parent, 'The (Un)importance of Existing: Community Sport Organisations’ Environmental Negotiations', returns the focus of the Special Issue to the United States and the universal challenge of securing sufficient resources to ensure sustainability. Based on document analysis and a series of semi-structured interviews and utilising resource dependency theory, the authors provide an insight into the motivations of managers of community sport organisations (CSO) and suggest that, as has been found in other countries, CSOs, unlike commercial organisations, do not always seek membership increases and market share expansion. The paper provides further evidence of the differences in strategic ambitions between for-profit and not-forprofit sports clubs. The paper also highlights the distinctiveness of the US sport environment and especially the importance of high-school and college sports organisations for the activities of CSOs.

The paper by Houlihan and Chapman focuses on elite disability youth sport with the empirical data drawn from three sports: wheelchair basketball, disability tennis and Boccia. A central concern of the study is to draw conclusions regarding the extent of 
convergence between disability youth sport and able-bodied sport. Convergence is assessed along seven dimensions: motives; agenda and aspirations; contextualising discourse; implementation; inputs; momentum; and impact. The study explored the talent identification process for the three sports and the role played not only by the governing bodies of the sports but also by national governmental and non-governmental agencies. The authors also discuss the ways in which the welfare of the young elite athletes is protected. Among the conclusions of the study in relation to convergence was that the dimensions which exhibited the clearest evidence of convergence were those associated with 'motives', 'agenda and aspiration' and 'contextualising discourse/ideology/values'. The data from all three sports (in terms of investment in coaching, competition and training camps for example) indicated a high degree of uniformity in motives, aspirations and values. Although there were some continuing differences in the sources of funding between mainstream and disability sport there was considerable similarity between the three sports. The study also concluded that while it would be churlish to ignore the benefits of elite competition to the athletes involved, the evidence suggested that disability sport organisations find the maintenance of a balance between meeting the requirements of elite athlete development and meeting the needs of the rest of the membership problematic.

The paper by Jacobs, Smits and Knoppers, “'You don’t realise what you see”: The Institutional Context of Emotional Abuse in elite youth Sport', focuses on the issue of emotional abuse and the ways in which coaches and directors involved in high performance women's gymnastics position themselves in relationship to these discourses in such a manner that it legitimizes the ways they organize and coach the sport. Based on a series of ten semi-structured interviews with coaches and adopting a 
Foucauldian lens, the authors conclude that coaches and directors legitimized coaching behaviour by using discourses of pleasure, protection, performance and of coaching expertise. In addition, they assign responsibility for current coaching behaviour to athletes, parents, (other) coaches and global and national policies. By providing a perspective on the coach-athlete relationship from the point of view of coaches and performance directors the paper complements the earlier analysis of the perceptions held by athletes and their parents.

Strittmatter and Skille, in their paper 'Boosting Youth Sport? Implementation of Norwegian Youth Sport Policy through the 2016 Lillehammer Winter Youth Olympic Games’, utilise the neo-institutional concepts of organisational change and organisational reproduction to analyse the way in which the 2016 Lillehammer Youth Olympic Games have been incorporated into the delivery of the Norwegian youth sport policy. The data, drawn from a series of interviews with key stakeholders and also from observations of events designed to promote the policy, indicates that the primary focus for implementation was on the recruitment and education of young leaders rather than on the development of young coaches and the recruitment and retention of young athletes. Furthermore, the study also concludes part of the explanation for the uneven implementation of policy is, on the one hand the relative non-involvement of national sport federations and sports clubs and, on the other, the administrative complexity of the framework for policy delivery. The authors consequently cast doubt on the likely impact of the association with the Lillehammer YOG on the delivery of the Norwegian youth sport policy. 
The final paper, by Jones, Edwards, Bocarro, Bunds and Smith, provides an overview of the state of research into sport-based youth development, often referred to as positive youth development (PYD) initiatives. Using a theory of change to guide coding and analysis, the authors' findings demonstrate how various aspects of the change process (e.g., resources/inputs, outcomes, impacts) have been integrated into empirical research. In addition to identifying trends and gaps in the literature, the authors use this information to provide informed recommendations for future research in the area of sport-based PYD. Among the trends identified in the literature are that: the emphasis on assessing the impact of PYD on the individual (rather than on the community for example); contextual factors, such as the importance of the coach and teammates, tend to be studied separately from the study of the community and the school; and that there is often a lack of clarity at the programme level regarding objectives thus making programme evaluation problematic.

The collection of papers included in this special issue address a range of management and policy issues associated with the growing field of activity and research into youth sport. What the collection highlights is the breadth of policy and management-related issues that have been generated by the recent growth in governmental and sport organisational interest in youth sport at all levels from the community to elite performance. The introduction of major youth events such as the Youth Olympic Games and the European Youth Olympic Festival bring an influential set of policy actors into the policy arena for youth sport with the potential either to complement and strengthen the resource base for community youth sport or to draw scarce federation and club resources away from the generality of members and concentrate them on meeting the specialist needs of the elite. How youth sport policy articulates with general or adult 
sport policy and how potential and actual tensions are managed remain key areas for future research.

\section{References}

Central Council of Physical Recreation (1960) Sport and the Community, London: Eyre and Spottiswood limited.

Grix, J., \& Carmichael, F. (2012). Why do governments invest in elite sport? A polemic. International journal of sport policy and politics, 4(1), 73-90.

Grix, J., \& Houlihan, B. (2014). Sports Mega-Events as Part of a Nation's Soft Power Strategy: The Cases of Germany (2006) and the UK (2012). The British Journal of Politics \& International Relations, 16(4), 572-596.

Servaes, J. (2012). Soft power and public diplomacy: The new frontier for public relations and international communication between the US and China. Public Relations Review, 38(5), 643-651. 